\title{
Y
}

\section{SYSTEMATIC COMPARATIVE APPROACHES TO THE ARCHAEOLOGICAL RECORD}

\section{Laura Fortunato, University of Oxford and Santa Fe Institute}

Chapter 3 in The Emergence of Premodern States: New Perspectives on the Development of Complex Societies, edited by Jeremy A. Sabloff and Paula L.W. Sabloff (Santa Fe Institute Press, 2018).

ISBN: 978-1-947864-12-2 (hardcover), 978-1-947864-03-0 (paperback).

Increasingly, interdisciplinary research teams are coming together to try to establish regularities, over space and time, in the complex system that is the human phenomenon (see, for example, Kohler et al., chapter 6 in this volume). Although vocabulary and tools have changed, the questions that animate this research program bear striking similarity to those pursued by nineteenth-century intellectuals in a quest to establish universal laws shaping human affairs. In fact, that very quest provided the impetus for the emergence of what would later become distinct disciplines in the social and historical sciences, including anthropology ${ }^{1}$ and sociology (see Carneiro 2003; Harris 2001; Trigger 2006).

Why, then, is this interdisciplinary research program often met with skepticism, or even outright resistance, within anthropology?

In this chapter I provide a brief outline of developments in the history of anthropology leading to this state of affairs, in the hope of alleviating misunderstanding between those who support the interdisciplinary research program and those who oppose it. As a practical contribution toward this end, I then provide an overview of key established resources for systematic comparative approaches to the archaeological record. I conclude by discussing challenges and opportunities in this area at the interface with recent developments in related archaeological practice.

\footnotetext{
1I refer to anthropology as traditionally practiced in North American universities, encompassing archaeology as a subfield.
} 


\section{Historical Sketch}

In large part, the current state of affairs in anthropology can be attributed to the prevailing theoretical paradigm of the late nineteenth century, now known as evolutionism. ${ }^{2}$ Broadly, its aim was the reconstruction of human cultural development, understood as the self-evident trajectory from "simple" to "complex" forms of social organization documented in the archaeological and historical records. The ethnographic record contributed evidence of "primitive" contemporary populations, taken to represent earlier stages along the way from "savagery" to "civilization," with "advanced" European society as the end point. This use of the ethnographic data, known as the comparative method, was intended as the objective collection and sorting of facts. Any form of moral value judgment was explicitly rejected-in principle, at least. In practice, many self-proclaimed intellectuals with no credentials other than wealth and status used this approach to validate stereotypes, often biased by nationalistic interests. The myth of European superiority, with the inferiority of "primitive" societies it implied, was elevated to the status of scientific truth, typically on the basis of dubious information collected by amateur ethnologists and equally dubious standards of proof masquerading as accurate methodology (Carneiro 2003:chap. 2-5; Trigger 2006:chap. 3-6).

What started as a critique of this abuse of the ethnographic record (e.g., Boas 1896) eventually led to a reconsideration of the assumptions on which the paradigm rested. These include, for example, the preeminence of cultural parallelism over other processes, and the existence of universal standards of progress (see

\footnotetext{
2 The paradigm is sometimes referred to more specifically as classical evolutionism or social/cultural/sociocultural evolutionism. These terms emphasize the distinction, both historical and conceptual, with contemporary approaches to the study of our species in light of principles derived from evolutionary biology, including evolutionary anthropology and Darwinian archaeology. The branch of contemporary approaches focusing on the process of cultural evolution (defined as change over time in the distribution of cultural traits) is also distinct from evolutionism (e.g., Boyd and Richerson 1985; Cavalli-Sforza and Feldman 1981).
} 
Harris [2001:chap. 9-10] for discussion). Within a few decades, the paradigm had been rejected, with long-lasting repercussions for the disciplines it had given birth to. For example, key features of contemporary sociocultural anthropology can be traced back to the reaction against evolutionism in the formative decades straddling the nineteenth and twentieth centuries. Relevant features include the antipathy toward quantitative approaches and the focus on

If indeed there are regularities over space and time in the $\sim 35 \sim$ buman phenomenon, then they must be documented in the ethnographic and archaeological records. Naturally, antbropologists are best qualified to guide attempts to extract information from these sources.

field-based, site-specific investigation as the hallmark of training and practice. Comparative approaches are viewed with suspicion, even when they are completely detached, conceptually and methodologically, from the comparative method of evolutionism. More broadly, context-heavy description is preferred, and valued, over systematic explanation. Combined, these features set anthropology apart from cognate disciplines such as sociology, political science, and economics.

If indeed there are regularities over space and time in the human phenomenon, then they must be documented in the ethnographic and archaeological records. Naturally, anthropologists are best qualified to guide attempts to extract information from these sources. Yet the relative minority of anthropologists willing to engage with this research program tend to be cautious in their approach, aware that the odious excesses of evolutionism stemmed from nineteenth-century scientism. Furthermore, this minority 
operates among a majority who reject the research program on ideological grounds couched as methodological criticism, dismissing any scientific approach as reductionist.

Interdisciplinary research efforts continue to be hampered by this unfortunate state of affairs. My reading of the developments that led to it suggests that some caution is indeed justified, if past mistakes are to be avoided. Yet this attitude tends to frustrate researchers not familiar with the history of anthropology. As a result, the two "sides" often operate in opposition to each other,

$\sim 36 \sim \quad$ rather than in concert. The hope is that, in exposing the root cause of the tension, this brief historical sketch can lead to a more productive exchange between them.

\section{Systematic Comparison in Anthropology}

Approaches to comparative analysis in the social and historical sciences can be classified along a continuum from intensive to systematic. Intensive approaches typically involve many variables across few cases, while systematic approaches typically focus on few variables across many cases (Smith and Peregrine 2012:7-9).

To varying degrees, anthropologists are comfortable with intensive comparative approaches, generally applied informally (Trigger 2003:chap. 2). For example, it is common practice to compare and contrast societies on subsistence regime, form of social organization, and so on, to aid in interpretation of patterns and phenomena documented in the ethnographic and archaeological records. Systematic comparative approaches are more contentious, especially when coupled with formal treatment of the data (i.e., statistical analysis and/or mathematical modeling). Inevitably, there tends to be a trade-off between the number of cases and variables, on the one hand, and the amount of context (historical, ethnographic, etc.), on the other. Consequently, systematic approaches typically involve the sacrifice of detail for larger samples that are 
amenable to quantitative analysis. To many anthropologists the trade-off bears echoes of the comparative method of evolutionism. ${ }^{3}$

This attitude has stifled the application of systematic comparative approaches in anthropology throughout the twentieth century (Murdock 1971). At the same time, it has spurred methodological developments to address specific criticisms raised (see discussions of the key issues in Burton and White [1987]; Ember and Ember [2009]). One such development is the production of standard samples of cases, drawn from the ethnographic record, specifically for systematic comparative analysis. ${ }^{4}$ For example, Murdock and White (1969) collated the Standard Cross-Cultural Sample with the aim of adequately representing the range of cultural variation documented in the ethnographic record-that is, avoiding biases toward regions that are overrepresented. At the same time, they sought to minimize the effects of the nonindependence of human societies, arising from processes such as descent from a common ancestor and diffusion through contact ${ }^{5}$ (Murdock 1977). Further, by establishing a standard sample, Murdock and White (1969) aimed to facilitate integration of data and findings across studies. This strategy proved successful: currently, the Standard CrossCultural Sample codebook includes coded data on approximately 2,000 variables for the 186 societies in the sample (White et al. n.d.).

In addition to these "endogenous" developments, systematic

3 Indeed, the application of statistical thinking to cross-cultural samples drawn from the ethnographic record was pioneered in this context, with a paper presented by Tylor (1889) to the Royal Anthropological Institute in 1888-according to Harris (2001:158), "[p]erhaps the greatest anthropological paper of the nineteenth century."

4 Ember and Ember (2009:93-107) provide an overview of available cross-cultural samples, standard and otherwise, including a discussion of the advantages and disadvantages of each.

5 The issue of the nonindependence of sample units in comparative analysis was first recognized by Galton in response to Tylor's 1888 paper; Galton's comments are summarized in Tylor (1889). To this day, the issue of nonindependence is known in anthropology as "Galton's problem." It is worth noting that not all researchers agree that Galton's problem poses a threat to systematic comparative analysis in anthropology (for example, see discussion in Ember and Ember [2009:107-110]). 
comparative analysis of the ethnographic record has benefited from exchanges with other disciplines. For example, since the 1970s researchers interested in the evolution of human social behavior have used this approach to uncover patterns in behavioral diversity across groups. In turn, they have contributed hypotheses (e.g., Alexander et al. 1979) and methods (e.g., Mace and Pagel 1994) from the biological sciences.

Analogous developments for systematic comparative analysis of the archaeological record have lagged behind (see discus$\sim 38 \sim \quad$ sion in Peregrine [2004]). As a result, the available resources are less known, and less used, than their ethnographic counterparts. I briefly outline the key established resources below before reviewing some challenges associated with their use. I conclude by discussing the interface with recent developments in related archaeological practice. More general overviews of comparative approaches in archaeology can be found in Peregrine (2001a, 2004) and Trigger (2003:chap. 2).

\section{RESOURCES FOR SYSTEMATIC COMPARISON IN ARCHAEOLOGY}

The major established tool for systematic comparative analysis of the archaeological record encompasses two resources developed by the Human Relations Area Files (HRAF) beginning in the late1990s (http://hraf.yale.edu/): its online archaeological database, eHRAF Archaeology, and the Encyclopedia of Prehistory (Peregrine and Ember 2002). Both resources, described below, are used extensively across chapters in this volume (see, especially, chapters 7 and 9).

\section{The "Archaeological Tradition" as Unit of Analysis}

In an effort to address the shortcomings of previous research, development of the HRAF resources focused on the production of a standard sample of cases drawn from the archaeological record, large enough to allow for formal treatment of the 
data (Peregrine 2004). A key issue was defining an appropriate unit of analysis. Comparative research hinges on definition of comparable units, allowing for both generality and specificity. In archaeology, generality ensures that the definition is applicable to data from any region and time period, while specificity ensures that distinct cases remain readily distinguishable (Peregrine and Ember 2001-2002:vol. 9:2).

The HRAF resources use the "archaeological tradition" as unit of analysis. This is defined as "a group of populations sharing similar subsistence practices, technology, and forms of socio-political organization, which are spatially contiguous over a relatively large area and which endure temporally for a relatively long period" (Peregrine 2001b:ii).

Archaeological traditions have both a spatial and a temporal dimension: as a rule of thumb, minimal area coverage is on the order of $100,000 \mathrm{~km}^{2}$, and minimal temporal duration is on the order of five centuries. The focus is on information that can be recovered from the archaeological record (e.g., subsistence practices and sociopolitical organization) as opposed to more labile traits typically used in the definition of "cultures" in ethnography (e.g., language or ideology). Consequently, an archaeological tradition may or may not correspond to a "culture" as defined for the purpose of comparative analysis of the ethnographic record (Peregrine and Ember 2001-2002:vol. 9:2).

\section{The Outline of Archaeological Traditions}

Based on the above definition, Peregrine (2001b) developed the Outline of Archaeological Traditions $(O A T)$ as a catalog of all known archaeological traditions documenting human prehistory.

The main focus in developing the $O A T$ was on extracting units roughly equivalent across areas (Peregrine and Ember 20012002:vol. 9:2-3), covering the entire period from the origin of the genus Homo in Africa approximately two million years ago to 
European exploration and colonization of Oceania, the Americas, and sub-Saharan Africa approximately 500 years ago. The current version includes 289 entries (Peregrine 2001b, revised 2010).

\section{eHRAF Archaeology}

The $O A T$ is the sampling frame for eHRAF Archaeology, HRAF's online archaeological database (http://hraf.yale.edu/products/ ehraf-archaeology/). To the extent that the $O A T$ is a comprehensive list of all prehistoric human societies known archaeologi$\sim 40 \sim \quad$ cally (Peregrine 2004) —an assumption I discuss below-then a random sample drawn from it will be a representative snapshot of human prehistory. Based on this reasoning, eHRAF Archaeology provides information for a simple random sample of archaeological traditions in the $O A T$. In addition to the random sample, it provides information on complete sequences of archaeological traditions for selected world regions.

eHRAF Archaeology is continually expanding and updated annually. At the time of going to press, it covered 99 archaeological traditions overall, 48 of which are included in the random sample, with complete sequences for Egypt, Mesopotamia, the Highland and Coastal Andes, Highland Mesoamerica, the Maya area, the Mississippi River Valley, the Indus Valley, and the U.S. Southwest (C. Ember, personal communication, October 2017).

In addition to a general summary for each tradition, the database provides full-text source documents, including books, journal articles, dissertations, and manuscripts. The documents are numerically subject indexed, paragraph by paragraph, following the Outline of Cultural Materials (Murdock et al. 2008), a vast compendium of indexing terms that seeks to cover all aspects of human social and cultural life. This indexing system, unique to HRAF databases, ${ }^{6}$ allows users to search for and connect related

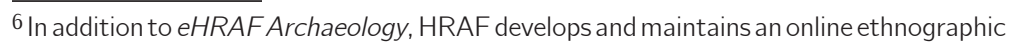
database, eHRAF World Cultures (http://hraf.yale.edu/products/ehraf-world-cultures/). 
anthropological concepts across documents, irrespective of the language of the documents, the specific terms used, and spelling conventions. For example, a simple keyword search for "metalworking" or "smithing" would fail to retrieve related information expressed with different terms or in a language other than English. A search based on relevant subjects in the Outline of Cultural Materials (325: metallurgy; 326: smiths and their crafts; 327: iron and steel industry; 328: nonferrous metal industries) would instead retrieve, ideally, all related information available across documents in the database.

\section{The Encyclopedia of Prehistory}

Peregrine and Ember's (2001-2002) nine-volume Encyclopedia of Prehistory provides descriptive information and references for 286 of the 289 archaeological traditions in the $O A T$ - that is, the 286 traditions unanimously deemed "prehistoric" (Peregrine and Ember 2001-2002:vol. 9:3).

In addition to details of the archaeological record and the environment pertaining to each tradition, topics covered include the tradition's settlement pattern, economy, sociopolitical organization, religion, and expressive culture (Peregrine and Ember 2001-2002:vol. 1:x). Also included is a list of the descendants for each tradition, as determined based on time and location (Peregrine and Ember 2001-2002:vol. 9).

\section{OUTSTANDING ISSUES}

Development of a working draft of the $O A T$ involved some 30 scholars over two years, called to revise and refine successive iterations of the list (Peregrine 2001b). Compilation of the Encyclopedia of Prehistory involved 200 scholars from 20 nations over four years (Peregrine and Ember 2001-2002:vol.9:2-3). eHRAF Archaeology is a work in progress started in the late 1990s. These figures point to the impressive scale of the projects and, more 
generally, to the benefits of collaborative work in systematic comparative archaeology. The range of applications of the resources across chapters in this volume illustrates how they can be used to help uncover trends and patterns in human prehistory. At the same time, awareness of the challenges encountered in using these resources can prove useful in guiding future efforts (see discussion in Peregrine and Ember [2001-2002:vol. 9:1-4]). I limit discussion to two issues as they apply specifically to systematic comparative analysis of the archaeological record: derivation of a sampling frame and the statistical nonindependence of sample units.

The $O A T$ is, effectively, an attempt to catalog all known prehistoric human societies (Peregrine 2004), intended as "a statistically valid sample of cases for comparative archaeological research" (Peregrine 2001a:12). But is it? One practical consideration is that, just like the ethnographic record, the archaeological record is biased. In archaeology, the bias will be toward wealthier areas and/or those with greater political stability-factors that facilitate archaeological fieldwork (Peregrine and Ember 20012002:vol.9:3). Thus, to the extent that the OAT and the Encyclopedia of Prehistory provide "a snapshot of our current knowledge of the archaeological record” (Peregrine and Ember 2001-2002:vol.9:3), they will reflect these biases, as will the random sample in $e H R A F$ Archaeology.

Further, any sample drawn from these resources will comprise units that are statistically nonindependent. This can result from contact between the populations captured by different archaeological traditions, or it can occur because the populations shared a common ancestor. Both processes may lead to greater similarity between archaeological traditions that are closer geographically, for example, compared to others. Additionally, because the $O A T$ is diachronic, two traditions in a sample drawn from it may represent populations that are one the direct descendant of the other. So, for 
example, if the earliest of these traditions developed metalworking, then it is likely that its descendant will also display metalworking. This would have to be taken into account in determining trends in,

The Outline of Archaeological Traditions is, effectively, an attempt to catalog all known prebistoric human societies, intended as "a statistically valid sample of cases for comparative archaeological research." But is it?

or correlates of, the acquisition of metalworking over the course of prehistory based on the sample (see discussion in Peregrine [2003]).

Accounting for the effects of all the processes described above poses nontrivial methodological challenges. Some of the issues have been discussed extensively in the ethnographic literature, as they also apply to systematic comparative analysis of the ethnographic record (see discussions in Ember and Ember [2009]; Levinson and Malone [1980]). For example, the issue of the statistical nonindependence of units in synchronic samples due to contact between populations or to descent from a common ancestor (i.e., Galton's problem) has attracted considerable attention, with possible recent solutions including the application of phylogenetic comparative methods (Mace and Pagel 1994) or of network autocorrelation analysis (Dow 2007). Efforts to explore how these approaches can be extended to systematic comparative analysis of the archaeological record are ongoing (P. Peregrine, personal communication, July 2015).

\section{FUTURE DIRECTIONS}

It is becoming increasingly clear that collaboration between anthropologists and data scientists will be crucial in addressing the 
underlying methodological issues. For example, as discussed above, the $O A T$ and related resources rest on definition of a "fixed" unit of analysis (the archaeological tradition) and a "fixed" set of units (the 289 traditions in Peregrine [2001b]). With the adoption of flexible digital tools for the acquisition of data, researchers will instead be able to refine the unit they use to reflect the question at hand (see, e.g., Turchin et al. [2015] for an application to historical data).

Better still, in the future researchers may be able to bypass the a priori definition of the unit of analysis altogether. Rather, the $\sim 44 \sim$ most appropriate unit for the question at hand will be "extracted" computationally from the data. For example, data-mining and machine-learning techniques may be used to establish comparable foci of social interaction across sites, based on statistical patterns in the frequency distributions of unearthed artifacts. These techniques have been fruitfully employed in the study of other cultural domains (e.g., Michel et al. 2011), following the digitization of large bodies of data. Their application now also seems within reach in archaeology, in light of recent efforts to establish digital repositories for the preservation and some forms of integration of primary data (including the raw data and contextual information) from archaeological investigations (e.g., Open Context, https://opencontext.org, Kansa [2010]; tDAR: the Digital Archaeological Record, https://www.tdar.org/, Center for Digital Antiquity [2015]).

The aggregation and integration of both legacy and newly generated data in dedicated repositories and databanks promises an ever-changing picture of the archaeological record-a picture that will become more and more focused as the data accumulate. Although several challenges remain (Kintigh 2015; Kintigh et al. 2015), the further development of digital infrastructure in this direction is likely to transform how systematic comparative archaeology is conducted, for example extending its scope from prehistory to history (recall that the $O A T$ and related resources are 
restricted to prehistory). Perhaps the most important transformation will rest with how the data themselves are used. By necessity, the typical mode of synthesis in archaeology (including any form of comparative analysis) relies on interpretations of the primary data

Discipline-wide efforts toward the development of digital infrastructure will be a crucial step in addressing archaeology's grand challenges-fundamental questions about the buman phenomenon whose answers 45 require information on "facts of the past."

by the original investigators, or even summaries of these interpretations by others (Kintigh et al. 2015). Interpretations and summaries several steps removed from the data can become entrenched in the literature as "facts," serving as the basis for subsequent work by archaeologists and researchers in other disciplines. However, they cannot be refined as more data or improved inferential procedures become available. By contrast, the ability to access and analyze the primary data directly will remove the need to rely on often outdated, or even flawed, interpretations and summaries, eventually leading to reassessment of erroneous "facts" in the literature (Atici et al. 2013). Additionally, the data will be more readily shared with researchers in other disciplines and combined with complementary sources of information, such as ecological data (Kintigh 2006).

More broadly, discipline-wide efforts toward the development of digital infrastructure will be a crucial step in addressing archaeology's grand challenges-fundamental questions about the human phenomenon whose answers require information on "facts of the past," such as long-term cultural dynamics or the interplay between ecological and social factors (Kintigh et al. 2014). For example, why, and how, do leaders emerge in some societies, and 
what sustains inequality in the long term? What drives the decline and eventual demise of societies? And how do societies respond to rapid environmental change? Tackling these and related questions will involve both synthetic work within archaeology and interdisciplinary collaboration, entailing substantial practical and intellectual challenges (Kintigh et al. 2015). The reward will be the ability to contribute to contemporary scientific and societal debates.

$\sim 46 \sim$

ACKNOWLEDGMENTS

I thank Carol Ember and Peter Peregrine for feedback.

\section{REFERENCES CITED}

Alexander, R. D., J. L. Hoogland, R. D. Howard, K. M. Noonan, and P. W. Sherman

1979 Sexual Dimorphisms and Breeding Systems in Pinnipeds, Ungulates, Primates, and Humans. In Evolutionary Biology and Human Social Behavior: An Anthropological Perspective, edited by N. A. Chagnon and W. Irons, pp. 402-435. Duxbury Press, North Scituate, Massachusetts.

Atici, L., S. W. Kansa, J. Lev-Tov, and E. C. Kansa

2013 Other People's Data: A Demonstration of the Imperative of Publishing Primary Data. Journal of Archaeological Method and Theory 20(4):663-681.

Boas, F.

1896 The Limitations of the Comparative Method of Anthropology. Science 4(103):901-908.

Boyd, R., and P. J. Richerson 1985 Culture and the Evolutionary Process. The University of Chicago Press, Chicago.

Burton, M. L., and D. R. White

1987 Cross-Cultural Surveys Today. Annual Review of Anthropology 16(1):143-160. 
Carneiro, R. L. 2003 Evolutionism in Cultural Anthropology: A Critical History. Westview Press, Boulder, Colorado.

Cavalli-Sforza, L. L., and M. W. Feldman

1981 Cultural Transmission and Evolution: A Quantitative Approach. Princeton University Press, Princeton, New Jersey.

Center for Digital Antiquity

2015 tDAR: the Digital Archaeological Record. Accessed June 22, 2015, from https://www.tdar.org/.

Dow, M. M.

2007 Galton's Problem as Multiple Network Autocorrelation Effects: Cultural Trait Transmission and Ecological Constraint. CrossCultural Research 41(4):336-363.

Ember, C. R., and M. Ember

2009 Cross-Cultural Research Methods. 2nd ed. AltaMira Press, Lanham, Maryland.

Harris, $M$.

2001 The Rise of Anthropological Theory: A History of Theories of Culture. Updated edition. AltaMira Press, Walnut Creek, California.

Kansa

2010 Open Context in Context: Cyberinfrastructure and Distributed Approaches to Publish and Preserve Archaeological Data. The SAA Archaeological Record 10(5):12-16.

Kintigh, K. W.

2006 The Promise and Challenge of Archaeological Data Integration. American Antiquity 71(3):567-578.

2015 Extracting Information from Archaeological Texts. Open Archaeology 1(1). DOI:http://dx.doi.org/10.1515/opar-2015-0004.

Kintigh, K. W., J. H. Altschul, M. C. Beaudry, R. D. Drennan, A. P. Kinzig, T. A. Kohler, W. F. Limp, H. D. G. Maschner, W. K. Michener, T. R. Pauketat, P. N. Peregrine, J. A. Sabloff, T. J. Wilkinson, H. T. Wright, and M. A. Zeder 2014 Grand Challenges for Archaeology. American Antiquity $79(1): 5-24$.

Kintigh, K. W., J. H. Altschul, A. P. Kinzig, W. F. Limp, W. K. Michener, J. A. Sabloff, E. J. Hackett, T. A. Kohler, B. Ludäscher, and C. A. Lynch

2015 Cultural Dynamics, Deep Time, and Data: Planning Cyberinfrastructure Investments for Archaeology. Advances in Archaeological Practice 3(1):1-15. 


\section{THE EMERGENCE OF PREMODERN STATES}

Levinson, D., and M. J. Malone

1980 Toward Explaining Human Culture: A Critical Review of the Findings of Worldwide Cross-Cultural Research. HRAF Press, New Haven, Connecticut.

Mace, R., and M. Pagel

1994 The Comparative Method in Anthropology. Current Anthropology 35(5):549-564.

Michel, J.-B., Y. K. Shen, A. P. Aiden, A. Veres, M. K. Gray, The Google Books Team, J. P. Pickett, D. Hoiberg, D. Clancy, P. Norvig, J. Orwant, S. Pinker, M. A. Nowak, and E. L. Aiden 2011 Quantitative Analysis of Culture Using Millions of Digitized Books. Science 331(6014):176-182.

Murdock, G. P.

1971 Anthropology's Mythology. Proceedings of the Royal

Anthropological Institute of Great Britain and Ireland (1971):17-24.

1977 Major Emphases in My Comparative Research. CrossCultural Research 12(4):217-221.

Murdock, G. P., C. S. Ford, A. E. Hudson, R. Kennedy, L. W. Simmons, and J. W. M. Whiting

2008 Outline of Cultural Materials. 6th ed. HRAF Press, New Haven, Connecticut. Revised with modifications.

Murdock, G. P., and D. R. White

1969 Standard Cross-Cultural Sample. Ethnology 8(4):329-369.

Peregrine, P. N.

2001a Cross-Cultural Comparative Approaches in Archaeology. Annual Review of Anthropology 30(1):1-18.

2001b Outline of Archaeological Traditions. HRAF Press, New Haven, Connecticut. Revised September 2010.

2003 Atlas of Cultural Evolution. World Cultures 14(1):2-88.

2004 Cross-Cultural Approaches in Archaeology: Comparative

Ethnology, Comparative Archaeology, and Archaeoethnology. Journal of Archaeological Research 12(3):281-309.

Peregrine, P. N., and M. Ember (editors)

2001-2002 Encyclopedia of Prebistory. Kluwer Academic/Plenum Publishers, New York.

Smith, M. E., and P. Peregrine

2012 Approaches to Comparative Analysis in Archaeology. In The Comparative Archaeology of Complex Societies, edited by M. E. Smith, pp. 4-20. Cambridge University Press, Cambridge. 
Trigger, B. G.

2003 Understanding Early Civilizations: A Comparative Study. Cambridge University Press, Cambridge. 2006 A History of Archaeological Thought. 2nd ed. Cambridge University Press, Cambridge.

Turchin, P., R. Brennan, T. E. Currie, K. C. Feeney, P. François, D. Hoyer, J. G. Manning, A. Marciniak, D. Mullins, A. Palmisano, P. N. Peregrine, E. A. L. Turner, and H. Whitehouse

2015 Seshat: The Global History Databank. Cliodynamics 6(1). http://www.escholarship.org/uc/item/9qx38718.

Tylor, E. B.

1889 On a Method of Investigating the Development of Institutions; Applied to Laws of Marriage and Descent. The Journal of the Anthropological Institute of Great Britain and Ireland $18: 245-272$.

White, D. R., M. L. Burton, W. T. Divale, J. P. Gray, A. Korotayev, and D. Khaltourina

n.d. Standard Cross-Cultural Codes. Retrieved August 31, 2007, from http://eclectic.ss.uci.edu/ drwhite/courses/SCCCodes.htm. 